Revista Brasileira de Farmacognosia Brazilian Journal of Pharmacognosy 21(3): 402-406, May./Jun. 2011

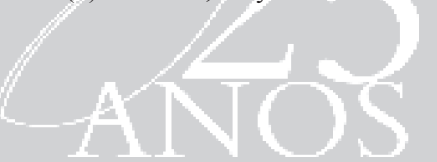

Article

Received 10 Aug 2010

Accepted 4 Nov 2010

Available online 20 Apr 2011

Keywords:

Myrcia uniflora

pedra-hume-caá

HPLC

myricitrin

standardization

ISSN 0102-695X

doi: 10.1590/S0102-695X2011005000066

\section{Development and validation of a HPLC method for standardization of herbal and commercial extracts of Myrcia uniflora}

\author{
Andrea N. de L. Batista, ${ }^{1}$ Renata Colombo, ${ }^{1}$ Inara C. de Pascoli, ${ }^{1}$ \\ Helder L. Teles, ${ }^{1}$ Geraldo H. Silva, ${ }^{1}$ Giovanni C. C. Bomfim, ${ }^{1}$ \\ Rosilene C. R. Burgos, ${ }^{1}$ Alberto J. Cavalheiro, ${ }^{* 1}$ Vanderlan da \\ Silva Bolzani, ${ }^{1}$ Dulce H. S. Silva, ${ }^{1}$ Maria Célia H. Reimberg ${ }^{2}$ \\ ${ }^{I}$ Departamento de Química Orgânica, Instituto de Química, Universidade Estadual \\ Paulista, Brazil, \\ ${ }^{2}$ Anidro do Brasil Extrações Ltda, Brazil.
}

\begin{abstract}
Myrcia uniflora Barb. Rodr., Myrtaceae, popularly known as "pedra-humecaá" in Brazil, is sold as dry extracts in capsules or as tinctures for the treatment of diabetes mellitus. Previous phytochemical studies on this species described the occurrence of the flavonoids mearnsitrin and myricitrin. In the present study, the chromatographic profiles of $M$. uniflora leaves and commercial extracts were determined using HPLC-PAD. Myricitrin was used as an external standard in the development and validation of the HPLC method. The proposed method is simple, rapid and reliable and can be successfully applied in industry for standardization of herbs and phytomedicines commercialised in Brazil as "pedra-hume-caá".
\end{abstract}

\section{Introduction}

People around the world employ a large variety of plant extracts for the treatment of many diseases. Among Myrtaceae family, species from Myrcia, Eucalyptus and Eugenia genera have popularly been used in the management of diabetes mellitus especially in developing countries (Bnouham et al., 2006). Myrcia uniflora Barb. Rodr., a plant popularly known as "pedra-hume-caá" in Brazil, is sold as dry extracts in capsules or as tinctures for the treatment of diabetes mellitus (Russo et al., 1990; Pepato et al., 1993; Ferreira et al., 2006). Previous phytochemical studies on this species described the occurrence of two known flavonoids: mearnsitrin and myricitrin (Ferreira et al., 2006). These flavonoid glycosides were found to inhibit rat lens aldose reductase (Yoshikawa et al., 1998; Matsuda et al., 2002). Aldose reductase is a key enzyme in the polyol pathway and has been reported to catalyze the reduction of glucose to sorbitol. Sorbitol does not readily diffuse across cell membranes, and its intracellular accumulation has been implicated in the chronic complications of diabetes such as peripheral neuropathy, retinopathy, and cataracts (Matsuda et al., 2002).
It is well accepted that for evaluating the quality of herbal medicines, it is necessary to standardize the content of the active principles. Moreover, the existing legislation in Brazil determines that a standardization method be developed in order to be used in the quality control of both raw plant material and phytomedicines. Therefore, if there is no previous report regarding the putative plant in an official compendium recognized by the National Health Surveillance Agency-Anvisa, the detailed analytical method to be used in the quality control of this phytopharmaceutical product, with properly validation based on Anvisa's validation guide, must be developed (Anvisa, 2010).

This work reports the development of a simple, rapid and reliable HPLC method, using the flavonol myricitrin (1) as phytochemical marker, for the analysis and quality control of both commercial herbal medicines and crude material sold as "pedra-hume-caá" in Brazil. The choice of myricitrin as phytochemical marker is justified in view of its potentiality for the treatment of diabetes mellitus (Yoshikawa et al., 1998; Matsuda et al., 2002). Several HPLC methods have been developed for the determination of flavonoids, including myricitrin, in complex matrices (Ducrey et al., 1995; Sakakibara et al., 2003; Michodjehoun-Mestres et al., 2009; Tung et al., 
2009; Yang et al., 2009) however, most of them present long chromatographic runs which may be prohibitive for some industrial applications. Furthermore, to the best of our knowledge, no previous HPLC method has been described for the analysis of Myrcia uniflora extracts. Finally, this work contributes to the comprehensive knowledge about $M$. uniflora given that very few studies have been carried out so far.<smiles>CC1(O)OC2OC1OC(Oc1c(-c3cc(O)c(O)c(O)c3)oc3cc(O)cc(O)c3c1=O)C2O</smiles>

1

\section{Material and Methods}

\section{Plant material and commercial extracts}

For this study two industrial extracts (dry powder, code 20665 and fluid, code 20700) as well as leaves (air-dried at ca. $40{ }^{\circ} \mathrm{C}$ and stored at room temperature $\left(25 \pm 2{ }^{\circ} \mathrm{C}\right)$ for six months) of Myrcia uniflora were utilized.

The commercial extracts and the sample of leaves were obtained from "Anidro do Brasil Extrações Ltda" industry (Botucatu, SP, Brazil). The plant material was identified by the industry botanical sector and confirmed by the quality control sector through histological tests.

\section{Chemicals and standard}

Acetonitrile and methanol were HPLC grade (J.T.Baker, Philipsburg, PA, USA). Acetic acid was analytical grade (Synth, Diadema, SP, Brazil). Water used in all experiments was purified in-house using a Milli-Q system (Millipore, São Paulo, SP, Brazil). Myricitrin authentic standard ( $>99 \%$ ) was purchased from Extrasynthese S.A (Genay, France).

\section{HPLC equipment}

The analytical separation was performed in a high performance liquid chromatographic-diode array system (HPLC-PAD) which consisted of two Shimadzu LC-6AD pumps (Kyoto, Japan), a degasser DGU-
20A5, an auto injector SIL-10AF, a photodiode array detector SPD-M20A used with a CBM-20A interface and a Phenomenex Luna ${ }^{\circledR}$ phenyl-hexyl column (250 $\mathrm{x} 4.6 \mathrm{~mm} ; 5 \mu \mathrm{m}, 100 \AA)$ protected by a phenyl-hexyl guard column $(4.0 \times 3.0 \mathrm{~mm} ; 5 \mu \mathrm{m}, 100 \AA)$. HPLC data acquisition was done by LCsolution software.

Sample preparation for HPLC analysis

For the dry powder extracts, $0.20 \mathrm{~g}$ was accurately weighted and sonicated with $10 \mathrm{~mL}$ of methanol $40 \%$ in water for $10 \mathrm{~min}$ at room temperature. An aliquot of 1 $\mathrm{mL}$ of this solution was submitted to SPE using C-18 AccuBond II $500 \mathrm{mg}$ cartridges (Agilent Technologies, Santa Clara, CA, USA), pre-conditioned with $2 \mathrm{~mL}$ of methanol $50 \%$ in water in order to retain lipophilic compounds. The fraction eluted with additional $2 \mathrm{~mL}$ of methanol $40 \%$ in water was taken in a volumetric flask and the final volume adjusted to $5 \mathrm{~mL}$. Finally, after filtration through a $0.22 \mu \mathrm{m}$ Millex Durapore ${ }^{\circledR}$ PVDF membrane (Millipore, New Bedford, MA, USA) $20 \mu \mathrm{L}$ was inject into the HPLC system.

The fluid extract sample was prepared as follow: $1 \mathrm{~mL}$ was diluted to $4 \mathrm{~mL}$ of methanol $40 \%$ in water and an aliquot of $1 \mathrm{~mL}$ of this solution was submitted to the same SPE procedure described above. In order to prepare the leaves extracts, $1.0 \mathrm{~g}$ of dried leaves was sonicated with $20 \mathrm{~mL}$ of methanol $40 \%$ in water for $40 \mathrm{~min}$ at room temperature, and an aliquot of $1 \mathrm{~mL}$ of this solution was also submitted to the SPE procedure described beforehand.

\section{HPLC analysis}

In preliminary chemical studies, the chromatographic profiles of the leaves and commercial extracts of $M$. uniflora were obtained using a mobile phase consisting of $1 \%$ aqueous acetic acid (solvent $\mathrm{A}$ ) and acetonitrile (solvent B) with linear gradient elution from 5 to $100 \%$ of $\mathrm{B}$, in $40 \mathrm{~min}$, at a flow rate of $1.0 \mathrm{mLmin}^{-1}$. Using these chromatographic conditions, it was possible to confirm the presence of myricitrin in the analyzed extracts by comparing the retention time and UV spectrum with those obtained for the commercial standard.

Optimization experiments allowed the establishment of the best chromatographic conditions to analytical separations of the components with a shorter run time. The optimized analytical separations were carried out using a mobile phase that consisted of $0.1 \%$ acetic acid in water (solvent $\mathrm{A}$ ) and acetonitrile (solvent B) with a multi step linear gradient: 0-10 min: 15 to $30 \%$ of $\mathrm{B} ; 10-20 \mathrm{~min}$ : 30 to $50 \%$ of $\mathrm{B} ; 20-21$ min: $50-15 \%$ of $\mathrm{B}$ and $21-30 \mathrm{~min}: 15 \%$ of $\mathrm{B}$. A flow rate of $1.0 \mathrm{mLmin}^{-1}$ at room temperature and injection volume of $20 \mu \mathrm{L}$ were employed. The UV spectra were recorded from 190 to $420 \mathrm{~nm}$ and the chromatogram 
monitored at the specific wavelength of $350 \mathrm{~nm}$.

Method validation (Anvisa, 2003; Ribani et al.; 2004)

Selectivity and specificity

Analyte purity across the peak eluting from the HPLC at a retention time corresponding to that of myricitrin was determined using the data derived from the PAD in association with the software resource provided by the LC workstation.

\section{Calibration curve}

Five solutions of different concentrations of myricitrin $\left(393.82,281.30,112.52,56.26\right.$ and $\left.22.50 \mathrm{mgL}^{-1}\right)$ were injected in triplicate and both the regression equation and linearity factor determined.

Repeatability and intermediate precision

The repeatability was estimated by assaying solutions containing three different concentrations of the extract in methanol (equivalent to 26.0, 91.5 and 308.0 $\mathrm{mgL}^{-1}$ of total myricitrin), with each analysis being carried out in triplicate by the same operator on the same day. Intermediate precision was determined by analyzing, in triplicate, one of the solutions employed in the repeatability test (equivalent to $308.0 \mathrm{mgL}^{-1}$ of total myricitrin) on two consecutive days and by another operator.

\section{Reproducibility}

The reproducibility was examined in another laboratory by carrying out the analysis on a Waters Alliance $^{\circledR} 2795$ liquid chromatographic system (Mifford, MA, USA) equipped with a Waters 996 photodiode array detector (PAD). A new myricitrin calibration curve was prepared with the same concentration range of the first one $\left(393.82,281.30,112.52,56.26\right.$ and $22.50 \mathrm{mgL}^{-1}$ ). Moreover, the same extract solution of the repeatability test was reanalyzed in triplicate in the second different laboratory. Precision was expressed in terms of the coefficient of variation (CV) and the maximum acceptable value of it was set at $5 \%$

\section{Accuracy and recovery}

The accuracy and recovery were determined by application of the developed method to three extract solutions spiked with three different concentrations of myricitrin (equivalent to $28.45,48.76$ and $132.1 \mathrm{mgL}^{-1}$ of total myricitrin). Samples of the dry powder extract were spiked with the three different concentrations of myricitrin described above and submitted to sonication and SPE procedure. An extract solution without spiking of myricitrin was utilized as white sample. The accuracy was evaluated by back-calculation and expressed as the percent deviation between the amount of myricitrin found (extracting the amount determined in the white sample) and the amount added at the three different concentrations examined.

Limit of detection (LOD) and limit of quantification (LOQ)

The LOD was calculated on the basis of the signal-to-noise ratio $(\mathrm{S} / \mathrm{N})$ of 3 , whilst the LOQ was determined at a $\mathrm{S} / \mathrm{N}$ of 10 . The noise level was measured during the analysis of one of the samples and involved a portion of the chromatogram that was separated from the region containing the myricitrin peak.

\section{Robustness}

Samples of the dry powder extract were submitted to sonication and SPE procedure as described in the Materials and Methods section. An aliquot (20 $\mu \mathrm{L}$ ) was quantified by HPLC using the described method and employing different conditions of the HPLC method to determine the method robustness. Two different values of flow rate $\left(0.9\right.$ and $\left.1.1 \mathrm{mLmin}^{-1}\right), \mathrm{pH}$ (3.33 and 3.25), initial gradient condition $(13 \%$ of $B$ and $20 \%$ of B) as well the analysis in two different lots of Phenomenex Luna ${ }^{\circledR}$ phenyl-hexyl columns (5296-24 and 5296-26) were employed to determine the method robustness.

The robustness was qualitatively evaluated in terms of variation in retention time or/and quantitatively evaluated in terms of myricitrin concentration (CV). The maximum acceptable value of $\mathrm{CV}$ was set at $5 \%$.

\section{Results and Discussion}

The preliminary analysis of fluid extract, dry powder extract and extract prepared by sonication from Myrcia uniflora leaves, made using a exploratory linear gradient $(5-100 \% \mathrm{~B}$ in $40 \mathrm{~min})$, presented similar chromatographic profiles for the three samples, showing several minor peaks and some intense peaks related to myricitrin besides others with UV spectra similar to flavonoids.

Optimization of the chromatographic conditions led to a more rapid and efficient separation of myricitrin from other extract components (Figure 1) when compared to methods previously described (Ducrey et al., 1995; Sakakibara et al., 2003; Michodjehoun-Mestres et al., 2009; Tung et al., 2009). In these conditions, the band purity as well as the validated method obtained allowed the quantification of myricitrin with good precision and 

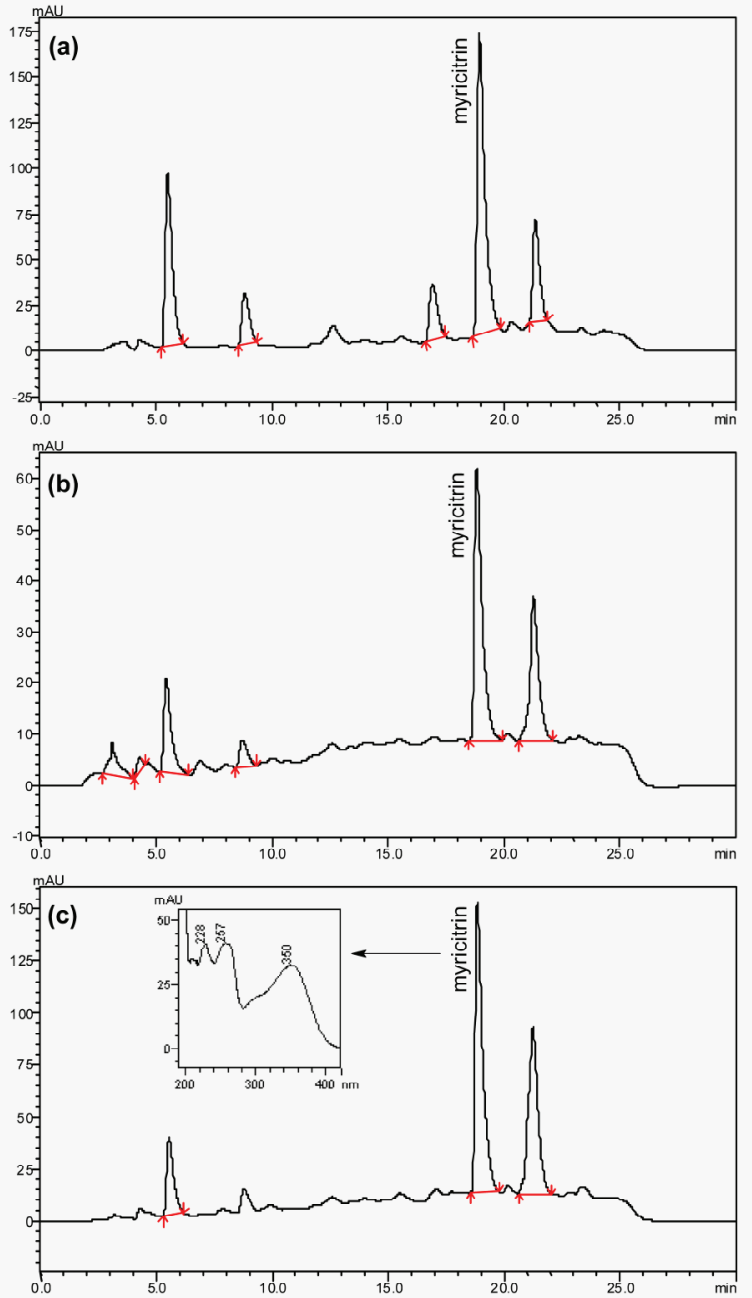

Figure 1. HPLC-PAD chromatograms of extracts of Myrcia uniflora leaves, recorded at $350 \mathrm{~nm}$ : (a) fluid extract, (b) dry powder extract and (c) extract of M. uniflora leaves obtained by sonication.

exaction in both the herbs and industrial extracts. Upon decreasing the concentration of acetic acid in the mobile phase from 1.0 to $0.1 \%$ no significant change in myrictrin peak shape was observed. In addition, the use of a simple UV detector make the method more accessible to be widely used in the quality control of herbal medicines made of $M$. uniflora.

The selectivity and specificity of the analytical method was confirmed from the purity angle and the purity threshold of myricitrin obtained using the PAD workstation software resource for the standard analyte and for each of the extracts assayed. The response of the UV detector at $350 \mathrm{~nm}$ was linear from 393.82 to 22.50 $\mathrm{mgL}^{-1}$ for myricitrin. The regression equation found was $y=0.000513 x+7.69$, with a correlation coefficient (r) of 0.9997 and a $\mathrm{CV}<2 \%$ for the analysis in triplicate (Table 1). The LOD and LOQ were $0.534 \mathrm{mgL}^{-1}$ and $1.78 \mathrm{mgL}^{-1}$, respectively.
Table 1. Results of the linearity of the method developed.

\begin{tabular}{ll}
\hline \multicolumn{1}{c}{ Parameters } & \multicolumn{1}{c}{ Results } \\
\hline Concentration range & $393.82-22.50 \mathrm{mgL}^{-1}$ \\
Calibration plot equation $(\mathrm{y}=\mathrm{ax}+\mathrm{b})$ & $\mathrm{y}=0.000513 \mathrm{x}+7.69$ \\
Correlation coefficient $(\mathrm{r})$ & 0.9997 \\
\hline
\end{tabular}

Regarding repeatability, the $\mathrm{CV}$ obtained for the three different concentrations analysed were $0.71,0.22$ and $0.97 \%$ and the $\mathrm{CV}$ for intermediate precision was $1.13 \%$ (Table 2).

The reproducibility was examined in two different laboratories. The second calibration curve presented linear response of the UV detector at 350 $\mathrm{nm}$ from 393.82 to $22.50 \mathrm{mgL}^{-1}$ for myricitrin. The regression equation found was $\mathrm{y}=0.000641 \mathrm{x}+17.20$, with a correlation coefficient (r) of 0.9972 and a $\mathrm{CV}<2 \%$ for the analysis in triplicate. The $\mathrm{CV}$ obtained from the results between the two laboratories was $1.85 \%$ (Table 2).

Table 2. Results of the repeatability, intermediated precision and reproducibility tests.

\begin{tabular}{|c|c|c|c|}
\hline Validation test & $\begin{array}{l}\text { Experimental } \\
\text { myricitrin } \\
\text { concentration } \\
\left(\mathrm{mgL}^{-1}\right)\end{array}$ & $\begin{array}{l}\text { Average of } \\
\text { experimental } \\
\text { myricitrin } \\
\text { concentration } \\
\left(\mathrm{mgL}^{-1}\right)\end{array}$ & $\mathrm{CV}(\%)$ \\
\hline \multirow{9}{*}{ Repeatability } & 26.42 & \multirow{3}{*}{26.24} & \multirow{3}{*}{0.71} \\
\hline & 26.25 & & \\
\hline & 26.05 & & \\
\hline & 91.50 & \multirow{3}{*}{91.51} & \multirow{3}{*}{0.22} \\
\hline & 91.72 & & \\
\hline & 91.32 & & \\
\hline & 306.42 & \multirow{3}{*}{308.46} & \multirow{3}{*}{0.97} \\
\hline & 311.91 & & \\
\hline & 307.06 & & \\
\hline \multirow{2}{*}{$\begin{array}{l}\text { Intermediated } \\
\text { precision }\end{array}$} & 305.20 & \multirow{2}{*}{307.65} & \multirow{2}{*}{1.13} \\
\hline & 310.10 & & \\
\hline \multirow{2}{*}{ Reproducibility } & 308.46 & \multirow{2}{*}{304.47} & \multirow{2}{*}{1.85} \\
\hline & 300.48 & & \\
\hline
\end{tabular}

The recoveries of myricitrin from the spiked extract solutions were $99.51,100.74$ and $97.60 \%$ in respect to each of the three concentrations analysed (Table 3 ).

The robustness test presented variation in the retention time and concentration of myricitrin showing that the method is sensitive to small variations of flow rate and mobile phase composition. Flow rate of 0.9 and $1.1 \mathrm{mLmin}^{-1}$ resulted in variation of retention time and concentration of myricitrin, with a CV of 10 and $12 \%$, respectively. The initial gradient conditions of $13 \%$ B and 20\% B resulted only in variation of myricitrin concentration with $\mathrm{CV}$ of 5.70 and $6.24 \%$, respectively. 
Analyses in different $\mathrm{pH}$ and columns did not alter the retention time of myricitrin and the $\mathrm{CVs}$ of concentrations found were of 1.13 and $1.23 \%$, respectively.

This study presented a rapid and reliable validated HPLC method, using myricitrin as marker, to the analysis of industrial extracts, commercial phytomedicines and herbs sold as "pedra-hume-caá" in Brazil.

Table 3. Results of the recovery test.

\begin{tabular}{lccc}
\hline Validation test & $\begin{array}{c}\text { Experimental } \\
\text { myricitrin } \\
\text { concentration } \\
\left(\mathrm{mgL}^{-1}\right)\end{array}$ & $\begin{array}{c}\text { Average of } \\
\text { experimental } \\
\text { myricitrin } \\
\text { concentration } \\
\left(\mathrm{mgL}^{-1}\right)\end{array}$ & Accuracy \\
\hline 28.24 & 28.31 & 99.51 \\
28.48 & & \\
28.21 & & \\
49.19 & & \\
49.09 & & \\
49.09 & & \\
130.50 & 128.90 .74 & \\
128.30 & & \\
128.00 & & \\
\hline
\end{tabular}

\section{Acknowledgments}

The authors thank Prof. Elizabeth Terán (in memorian) for her important contribution to this work, Anidro do Brasil Extrações Ltda (Botucatu, SP, Brazil) for the technical and financial support and $\mathrm{CNPq}$ for fellowships (grant no. 500185/2006-9).

\section{References}

Anvisa 2003. Resolução-RE no 899: Guia para validação de métodos analíticos e bioanalíticos. Diário Oficial da União. http://www.in.gov.br/imprensa/visualiza/ index.jsp? jornal $=1 \&$ pagina $=56 \&$ data $=02 / 06 / 2003$, accessed in October 2010.

Anvisa 2010. Resolução-RDC no 14: Dispõe sobre o registro de medicamentos fitoterápicos. Diário Oficial da União. http://www.in.gov.br/visualiza/index.jsp?data $=05 / 04 / 2010 \&$ jornal $=1 \&$ pagina $=85 \&$ total Arquivos $=$ 160 , accessed in October 2010

Bnouham M, Ziyyat A, Mekhfi H, Tahri A, Legssyer A 2006. Medicinal plants with potential antidiabetic activity - A review of ten years of herbal medicine research (1990-2000). Int J Diabetes Metab 14: 1-25.

Ducrey B, Wolfender JL, Marston A, Hostettmann K 1995. Analysis of flavonol glycosides of thirteen Epilobium species (Onagraceae) by LC-UV and thermospray LC-MS. Phytochemistry 38: 129-137.

Ferreira ACF, Neto JC, da Silva ACM, Kuster RM, Carvalho DP 2006. Inhibition of thyroid peroxidase by Myrcia uniflora flavonoids. Chem Res Toxicol 19: 351-355.

Matsuda H, Morikawa T, Yoshikawa M 2002. Antidiabetogenic constituents from several natural medicines. Pure Appl Chem 74: 1301-1308.

Michodjehoun-Mestres L, Souquet JM, Fulcrand H, Bouchut C, Reynes M, Brillouet JM 2009. Monomeric phenols of cashew apple (Anacardium occidentale L.). Food Chem 112: 851-857.

Pepato MT, Oliveira JR, Kettelhut IC, Migliorini RH 1993. Assessment of the antidiabetic activity of Myrcia uniflora extracts in streptozotocin diabetic rats. Diabetes Res 22: 49-57.

Ribani M, Bottoli CBG, Collins CH, Jardim ICSF, Melo LFC 2004. Validation for chromatographic and electrophoretic methods. Quim Nova 27: 771-780.

Russo EMK, Reichelt AAJ, De-Sá JR, Furlanetto RP, Moisés RCS, Kasamatsu TS, Chacra AR 1990. Clinical trial of Myrcia uniflora and Bauhinia forficata leaf extracts in normal and diabetic patients. Braz J Med Biol Res 23: 11-20.

Sakakibara H, Honda Y, Nakagawa S, Ashida H, Kanazawa K 2003. Simultaneous determination of all polyphenols in vegetables, fruits, and teas. J Agric Food Chem 51: 571-581.

Tung YT, Wu JH, Hsieh CY, Chen PS, Chang ST 2009. Free radical-scavenging phytochemicals of hot water extracts of Acacia confusa leaves detected by an online screening method. Food Chem 115: 1019-1024.

Yang X, Zhang X, Yuan Z, Li X, Zhang L, Fan L 2009. Simultaneous determination of myricitrin, hyperin, quercitroside, and quercetin in folium Rhododendri micranthi by RP-HPLC. J Chromatogr Sci 47: 714717.

Yoshikawa M, Shimada H, Nishida N, Li Y, Toguchida I, Yamahara J, Matsuda H 1998. Antidiabetic principles of natural medicines. II. Aldose reductase and alpha-glucosidase inhibitors from Brazilian natural medicine, the leaves of Myrcia multiflora DC. (Myrtaceae): structures of myrciacitrins I and II and myrciaphenones A and B. Chem Pharm Bull 46: 113119.

\section{*Correspondece}

Alberto J. Cavalheiro

Departamento de Química Orgânica, Instituto de Química, Univ Estadual Paulista, Caixa Postal 355, 14800-900 Araraquara-SP, Brazil albjcava@iq.unesp.br Tel. +551633019667 Fax +551633019692 